\title{
A Simulation Model for the Closed-Loop Control of a Multi-Workstation Production System
}

\author{
Juliana Keiko Sagawa $^{1}$ Michael Freitag $^{2}$ \\ ${ }^{1}$ Production Engineering Department, Federal University of São Carlos, Brazil (e-mail: juliana@dep.ufscar.br) \\ ${ }^{2}$ BIBA - Bremer Institut für Produktion und Logistik, Faculty of Production Engineering, University of Bremen, \\ Germany (e-mail: fre@biba.uni-bremen.de)
}

\begin{abstract}
In this paper, we propose a simulation model with a PI controller to analyze and control the dynamics of a multiworkstation production system. The formulation is based on dynamic modelling and control theory, and the model was implemented in Matlab and Simulink. Exploratory tests were carried out, and the results indicated some relationships between the values of the parameters of the controller and the values of the output variables, that is, the levels of work in process. They also showed that the proposed model has the potential of providing managerial directions on how to dynamically adjust the capacity, aiming to smooth the operation of the shop floor and to keep the work in process close to the desired levels.

Keywords: production systems, control theory, dynamics, simulation, planning and scheduling
\end{abstract}

\section{Introduction}

As known, the increasing computational capacity engendered a sound evolution of the operations management area, since it allowed the development of several tools to cope with large amounts of data related to the planning process and to ground the analysis of the decision makers. In this sense, the use of dynamic modeling and simulation techniques complements the static approaches for planning optimization of production systems and supply chains. Control theory is also a correlated area whose theories and tools have been applied to production and supply chain management. Some steps in these directions are enumerated in the literature review section of this paper.

Considering the aforementioned approaches, we present in this paper a simulation model based on state equations to depict the dynamics of a multi-workstation manufacturing system. A proportional-integral (PI) controller is applied to the model, and exploratory tests are carried out.

The model basically deals with the work in process (WIP) and capacity allocation variables (represented by the processing frequency of the stations), in a plant with job shop configuration. In general terms, the control of work in process is a classical concern in the operation of job shops, since it generates more predictable cycle/throughput times, which lead to better promises and fulfilment of delivery dates, a more stable coordination of the shop floor, and more flexibility to attend changes in the customer demand. These effects are highlighted in the literature related to various methodologies in production engineering, such as just-in-time, quick response manufacturing, workload control, factory physics, and others.

The results obtained with the simulation of the proposed model provided some indications of how its parameters influence the WIP levels, and demonstrated the potential of the proposed approach to depict the dynamic relations between capacity allocation, work in process and operations smoothness in production systems.

\section{Literature Review}

The effort of evolving from the static to the dynamic analysis of production and supply chain systems relies on system dynamics and control theory, as mentioned. In a broader sense, system dynamics may be defined as an area of knowledge that deals with the time-varying behavior of a system (Doebelin, 1998). This includes not only mechanical, electrical, fluid and thermal, but may also include biological, manufacturing, social and hybrid systems. Control theory, on its turn, has different subareas and a range of tools for the analysis and design of closedloop systems, where the information of the outputs is fed back to the system in order to lead it to desired goals. In the literature reviews concerning the application of control theory to production and supply chain, the models are classified according to the area of application [(Ortega and Lin, 2004), (Sagawa and Nagano, 2015b)], the underlying control methodology (Sarimveis et al., 2008), the type of analysis that is carried out (i.e. robustness, stability, etc.) (Ivanov and Sokolov, 2013), or according to mixed criteria (Åström and Kumar, 2014).

In Table 1, we present some applications of control theory to production and supply chain systems, classified according to subareas of application and the methods underlying the models. Our intention here is not to present an extensive review, but rather to enumerate different possibilities and to provide few references in each category, as examples.

Other applications based on model predictive control or robust optimal control are not listed here, but can be found in (Sarimveis et al., 2008). Also, there are some alterna- 
Table 1. Some Applications of control theory in production systems and supply chains

\begin{tabular}{|c|c|c|}
\hline $\begin{array}{l}\text { Area/type of appli- } \\
\text { cation }\end{array}$ & $\begin{array}{l}\text { Applied } \\
\text { methodolo- } \\
\text { gies and } \\
\text { tools }\end{array}$ & $\begin{array}{l}\text { References } \\
\text { (examples) }\end{array}$ \\
\hline $\begin{array}{l}\text { single-product } \\
\text { production- } \\
\text { inventory models } \\
\text { and extensions to } \\
\text { supply chain }\end{array}$ & $\begin{array}{l}\text { classical } \\
\text { control the- } \\
\text { ory, block } \\
\text { diagrams, } \\
\text { transfer } \\
\text { functions }\end{array}$ & $\begin{array}{l}\text { (Towell, } \\
\text { 1982; Zhou } \\
\text { et al., 2006; } \\
\text { Spiegler } \\
\text { et al., 2016) }\end{array}$ \\
\hline $\begin{array}{l}\text { production- } \\
\text { inventory models } \\
\text { with single and } \\
\text { multiple-machines } \\
\text { (with or without ad- } \\
\text { ditional constraints) }\end{array}$ & $\begin{array}{l}\text { dynamic pro- } \\
\text { gramming } \\
\text { and optimal } \\
\text { control }\end{array}$ & $\begin{array}{l}\text { (Scarf, 1960; } \\
\text { Boukas and } \\
\text { Liu, 2001; } \\
\text { Gharbi and } \\
\text { Kenne, 2003) }\end{array}$ \\
\hline $\begin{array}{l}\text { multi-echelon } \\
\text { production- } \\
\text { inventory mod- } \\
\text { els using bills of } \\
\text { material as input }\end{array}$ & $\begin{array}{l}\text { input-output } \\
\text { analysis, } \\
\text { Laplace or } \\
\text { Z-transform, } \\
\text { probability } \\
\text { distributions, } \\
\text { NPV }\end{array}$ & $\begin{array}{l}\text { (Axsäter, } \\
\text { 1976; Grubb- } \\
\text { ström and } \\
\text { Molinder, } \\
\text { 1994; Grubb- } \\
\text { ström et al., } \\
\text { 2010) }\end{array}$ \\
\hline $\begin{array}{l}\text { multiple-machine } \\
\text { and multi-product } \\
\text { systems based on } \\
\text { flow models }\end{array}$ & $\begin{array}{l}\text { flow mod- } \\
\text { els, block } \\
\text { diagrams, } \\
\text { transfer func- } \\
\text { tions, bond } \\
\text { graphs }\end{array}$ & $\begin{array}{l}\text { (Wiendahl } \\
\text { and Brei- } \\
\text { thaupt, 2000; } \\
\text { Kim and } \\
\text { Duffie, 2006; } \\
\text { Sagawa and } \\
\text { Nagano, } \\
\text { 2015a) }\end{array}$ \\
\hline $\begin{array}{l}\text { supervisory/process } \\
\text { control of contin- } \\
\text { uous production } \\
\text { systems and its } \\
\text { integration within } \\
\text { the hierarchical } \\
\text { production planning }\end{array}$ & $\begin{array}{l}\text { mixed inte- } \\
\text { ger dynamic } \\
\text { optimization } \\
\text { (MIDO), } \\
\text { mixed } \\
\text { integer non- } \\
\text { linear pro- } \\
\text { gramming } \\
\text { (MINLP) }\end{array}$ & $\begin{array}{l}\text { Monfared } \\
\text { and Yang, } \\
2007 ; \quad M u- \\
\text { nawar and } \\
\text { Gudi, 2004; } \\
\begin{array}{l}\text { Du et al., } \\
2015)\end{array}\end{array}$ \\
\hline $\begin{array}{l}\text { production and sup- } \\
\text { ply chain models } \\
\text { with autonomous } \\
\text { control/decentral- } \\
\text { ized agents }\end{array}$ & $\begin{array}{l}\text { queue length } \\
\text { estimator } \\
\text { (QLE), } \\
\text { pheromone, } \\
\text { heuristic } \\
\text { methods, } \\
\text { RFID }\end{array}$ & $\begin{array}{l}\text { (Scholz- } \\
\text { Reiter } \\
\text { and } \\
\text { itag, 2007; } \\
\text { Wang and } \\
\text { Lin, 2009; } \\
\text { Barenji } \\
\text { et al., 2014; } \\
\text { Schukraft } \\
\text { et al., 2016) }\end{array}$ \\
\hline
\end{tabular}

tive formulations out of the control theory area, based, for instance, in queueing systems, which are out of the scope of this paper.

In the following subsection, we present the mathematical model that was adopted as basis for the simulation model proposed in this paper.

\subsection{Dynamic multi-workstation model based on electrical components}

A dynamic model based on the ideal properties of electrical components is proposed in (Sagawa and Nagano, 2015a) to depict a multi-workstation system that can manufacture different families of products. The model is basically composed by machines, buffers and junction elements.

The machines are compared to resistors and their processing frequency $U_{i}$ correspond to $\frac{1}{R}$, where $R$ is an ideal resistance. Similarly, the buffers are seen as ideal capacitors with capacitance $C$, which corresponds to their storage capacity (Ferney, 2000). The junctions are used to couple these manufacturing elements and to depict the configuration of the production flow in the system, i.e. to represent the different process routings of each product or product family (Sagawa and Nagano, 2015a). When a given machine outputs flow to $m$ workstations downstream, it is coupled to these workstations by means of a divergent junction that imposes the conservation of flow. Similarly, the upstream flows coming from different workstations to a given workstation are merged by means of a convergent junction that conserves the total flow (Sagawa and Nagano, 2015a; Ferney, 2000). The discussed model is continuous and deals with 3 variables: the production flow $f$, the production volume $q$ and the effort $e$. The production volume corresponds to the integral of the flow, and the effort is used as an auxiliary variable, for coupling a machine and its precedent buffer, as well for the approximation of a discrete system as a continuous system (Ferney, 2000). The basic equation of the model is derived from the well-known constitutive equations of the ideal electrical components previously mentioned, and is shown in (1). The variables and parameters of this equation were already mentioned in the text. The index $i$ denotes a given workstation, the index $s$ applied to the flow or effort variables denotes the output of this station, and the index $e$ denotes its input. Eq. (2) is based on the aforementioned integral relation between the production volume $q$ and the flow variable $f$, likewise the electric charge stored in a capacitor is defined as a function of the integral of the electric current. In the context of manufacturing, $\dot{q}_{i}(t)$ is interpreted as a rate of material storage or consumption, expressed as the difference between the input and output flow of a workstation.

$$
\begin{array}{r}
f_{s i}=U_{i}\left[\frac{q_{i}(t)}{C_{i}}+\min \left\{1, q_{i}(t)\right\}-e_{s i}(t)\right] \\
\dot{q}_{i}(t)=f_{e i}(t)-U_{i} \min \left\{1, q_{i}(t)\right\}
\end{array}
$$




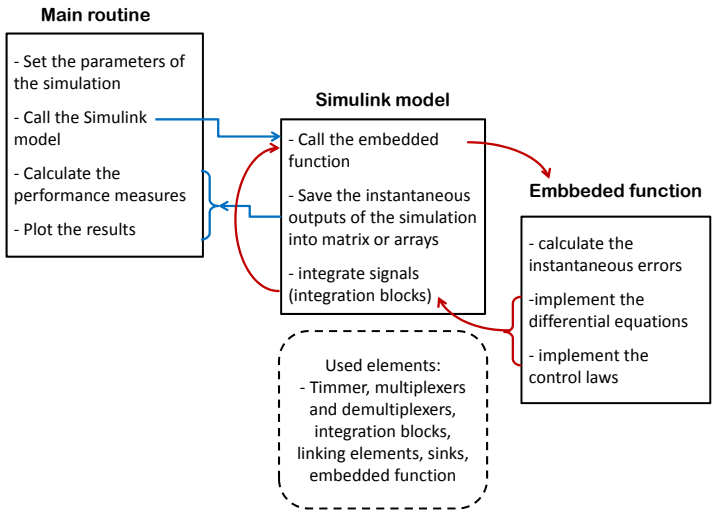

Figure 1. Schematics of the simulation model

The assumption of buffers with unlimited capacity allows simplifying (1), and the combination of (1) and (2) yields the basic state equation of a workstation, presented in (3).

$$
\dot{q}_{i}(t)=f_{e i}(t)-U_{i} \min \left\{1, q_{i}(t)\right\}
$$

This basic equation and the constitutive equations of the junctions were applied to a 11-workstation production system, as presented in (Sagawa and Nagano, 2015a), resulting in the state model shown in (4).

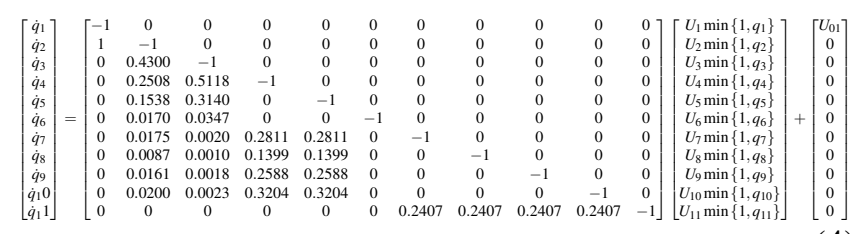

(4)

\section{Simulation Model with a PI Con- troller}

A simulation model based on the presented state equations was implemented using Matlab ${ }^{\circledR}$ and Simulink ${ }^{\circledR}$. It included a proportional-integral (PI) controller, as mentioned. The structure of this model, as well as the executed instructions, are shown in Fig. 1. As it can be seen, the relevant parameters of the simulation are defined in the main routine. After that, this routine calls the Simulink model (Fig. 2), which contains the block diagram of the dynamic model with the controller. The computation of the state equations is performed by a user-defined function embedded in the Simulink ${ }^{\circledR}$ model.

After the iterations are carried out for the total simulated time, the main routine compiles the results and calculates the performance measures. For the implementation of a proportional-integral controller, integration blocks $(1 / s)$ of the first level should be applied to the instantaneous material storage rates $\dot{q}_{i}$, while second level integrations should be applied to the relative errors in the stock levels, as it can be seen in Fig. 2.

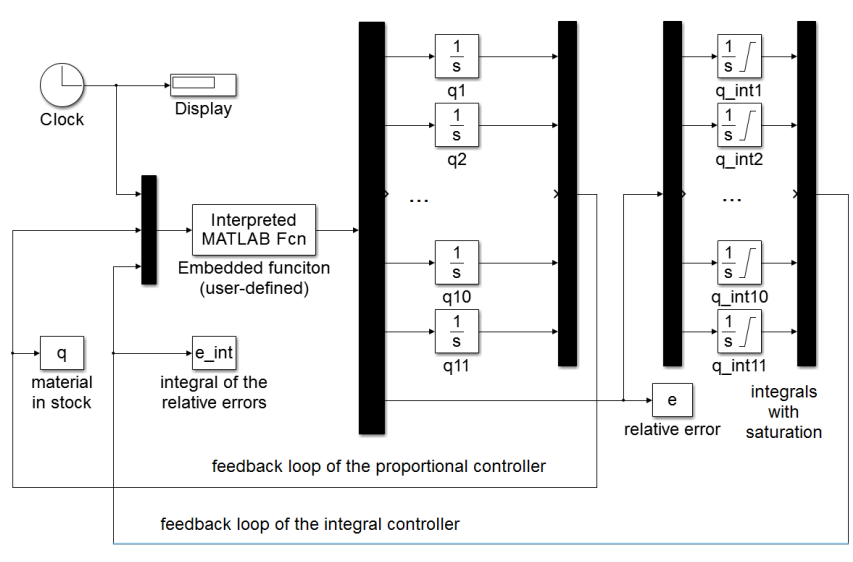

Figure 2. Schematics of the model build in Simulink ${ }^{\circledR}$

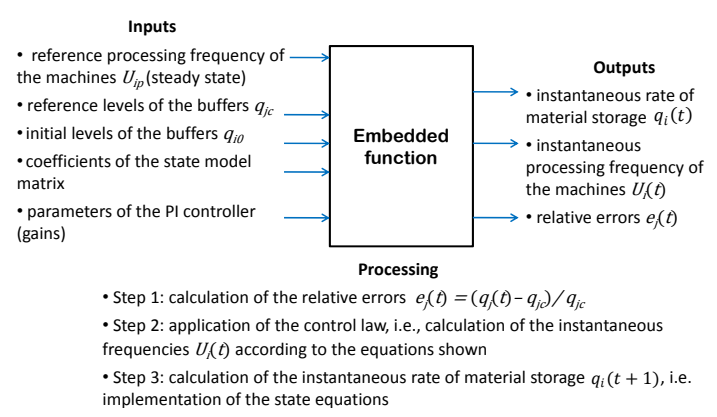

Figure 3. User-defined function implemented in the simulation model

As mentioned, the state model is implemented by means of a user-defined function. The inputs of this function are those parameters defined in the main routine, and presented in Fig. 3.

With these inputs, the function calculates, at each time $t$, the relative errors of the stock levels, shown in (5), and implements the control law. For an integral controller, this control law is shown in (6). With the values of the instantaneous processing frequencies of the machines $U_{i}$, resulting from the implementation of the control law, the instantaneous rates of material storage $\dot{q}_{i}(t+1)$ are then calculated. These rates are integrated in the integration blocks and fed back to the model

$$
\begin{array}{r}
e_{j}^{\prime}(t)=-e_{j}(t)=\frac{q_{j c}-q_{j}(c)}{q_{j c}} \\
U_{i}(t)=U_{i p}\left(1+k_{p} e_{j}^{\prime}(t)+k_{i} \int e_{j}^{\prime}(t) d t\right)
\end{array}
$$

where $\dot{q}_{j}(t)$ is the instantaneous amount of material stored in buffer $j, e_{j}^{1}(t)$ is the relative error considering the actual level $\dot{q}_{j}(t)$ and the reference level $q_{j c} ; U_{i p}$ is the reference for the processing frequency of machine $i$, considering the customer demand fulfillment in the steady state; $k_{p}$ is the proportional gain of the controller; and $k_{i}$ is the integral gain. The presented equations apply for the case where the buffer $j$ immediately succeeds the machine $i$. If machine $i$ is succeeded by more than one buffer, the minimum value of $e_{j}$ is computed. 


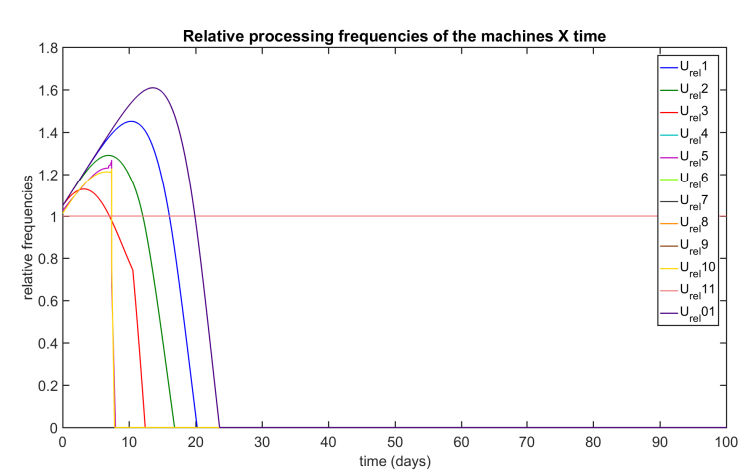

Figure 4. Processing frequencies of the machines for a test carried out with $k_{p}=0.05$ and $k i=0.05$ (whitout saturation limits).

\section{Test and Results}

The proposed simulation model was applied to the 11workstation system presented in (Sagawa and Nagano, 2015a). For an initial analysis, it was of interest to consider the warm-up of the manufacturing system and its transition to the regular operation, that is, to consider the situation where all the buffers are empty $(q i 0=0$ for all $i$ ) and the system starts to work, aiming to attend the customer demand and to reach the desired levels of work in process. This starting condition is somewhat similar to the application of a step input, conventionally used for the study of the response in dynamic systems. In our case, however, each buffer has a different reference level, since these levels were defined as a multiple of the amount of material cumulated in each buffer when the system was simulated without control, i.e., when the open-loop system was simulated. In order to allow comparisons, we adopted a multiplication factor of 100 times, as in (Sagawa and Nagano, 2015a). As output variables of the tests, we analyzed the values of the processing frequencies of the machines $U_{i}(t)$ (the controlled variables); the relative processing frequencies, i.e. $\left(U_{i}(t)-U_{i p}\right) / U_{i p}$; and the relative errors in the buffer levels $\left(e_{i}\right)$ over time. This last measure indicates the variation of the work in process in the system. Depending on the selected values of the gains, the machines are led to operate with processing frequencies above the reference frequencies, in order to fulfill the buffers. In Fig. 4, the source of material works with a processing frequency that is $60 \%$ greater than the frequency that attends the customer demand in the medium term, i.e. in the steady state. This control command generates a surplus of material in the buffers. When the controller receives this information, it reduces the processing frequency of the machines. This reaction, however, is excessive, so that the machines are shutdown. The saturation of the integral controller could be a relevant parameter of influence for the control of the processing frequencies of the machines. Due to the saturation in PI controllers, the integrator may drift to undesirable values, since it tends to produce progressively larger control signs. This effect is known as windup of the integral controller ( $F$ Franklin

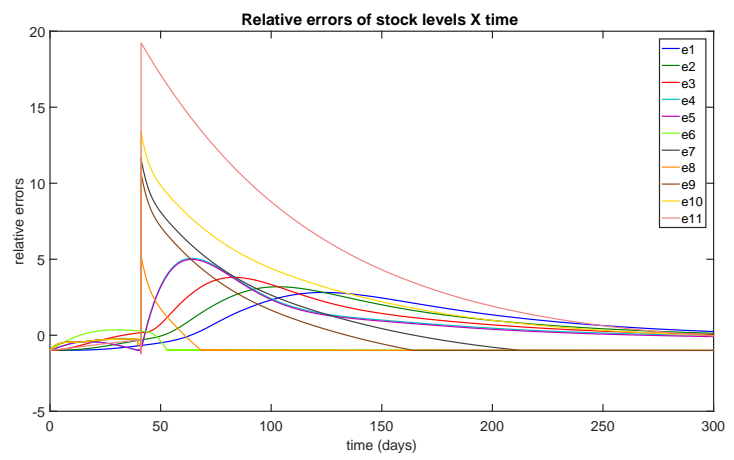

Figure 5. Evolution of the relative errors in stock levels (WIP), for saturation limits of $\pm 10, k_{p}=0.05$ and $k_{i}=0.001$.

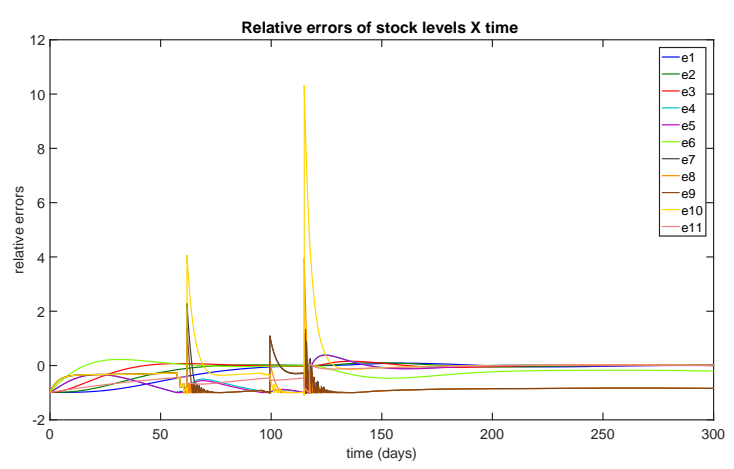

Figure 6. Evolution of the relative errors in stock levels (WIP), for saturation limits of $\pm 1, k_{p}=0.05$ and $k_{i}=0.001$.

et al., 1994; Moreno-Valenzuela, 2008). Therefore, additional tests were performed with the establishment of saturation limits for the integral controller. Some results are shown in Fig. 5-8. The values of the gains were kept constant and different saturation limits were tested.

The presented results indicate that, with narrower saturation limits, the overshoots in the WIP (represented by the relative errors) were significantly reduced. In Fig. 5, the overshoot is of 20 times the reference level and in Fig. 5, it is of 10 times. Although punctual instabilities in the control of some machines arose (Fig. 7), the operation of the system also became smoother with the estab-

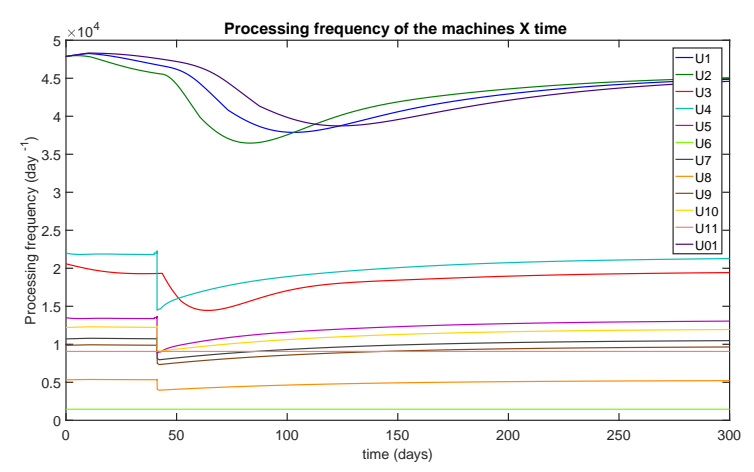

Figure 7. Evolution of the processing frequency of the machines, for saturation limits of $\pm 10, k_{p}=0.05$ and $k_{i}=0.001$. 


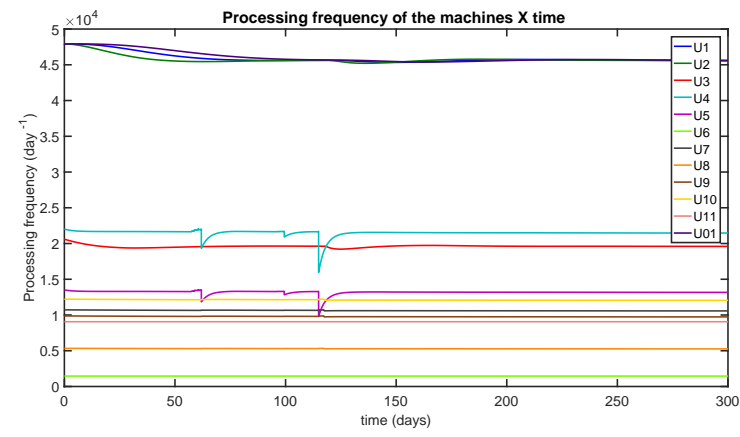

Figure 8. Evolution of the processing frequency of the machines, for saturation limits of $\pm 1, k_{p}=0.05$ and $k_{i}=0.001$.

lishment of saturation limits.

The exploratory tests have also shown that the overshoot in the processing frequencies of the machines tend to increase with the increase of the integral gain. Hence, the results could be further improved by means of systematic experiments and the application of control tools for the optimization of these parameters (gains and saturation limits).

From the managerial perspective, the controller can lead the system to undesired operating points, depending on parameters set, because working either too far above or below the regular capacity imply higher operational costs. Moreover, there are well-known relations among WIP, cycle times and throughput rate. An increase in WIP may engender a relevant increase in the cycle time (lead time), without producing any effect in the throughput rate of the production system (Hopp and Spearman, 2001). Longer cycles times usually result in delayed jobs, rush orders, and difficulty of coordination. Based on the aforementioned reasons, it is of interest, in our model, to find the parameters that enable to reduce the overshoot of WIP and, meanwhile, to reduce the oscillations in the processing frequencies of the machines.

The variations in the processing frequencies represent, in fact, capacity additions or reductions. Thus, the proposed simulation model may provide insights on how much capacity should be increased or decreased over time in order to: 1. guarantee adequate levels of WIP, to absorb fluctuations; 2 . avoid an excessive increase in the cycle/throughput times; 3 . smooth operations, so that the operational costs stay low. These capacity adjustments can be implemented in various ways, i.e. overtime, subcontracting, adding/renting extra resources, or reducing the utilization of the machines.

In practice, the goal of production managers is to keep the operations stable, as much as possible, so that no extra costs are incurred (although this pursuit of stability should not unreasonably compromise the flexibility to attend customers). In MRP systems, the short term variations in the plans are usually smoothed or prevented by applying time fences to demand, planning and/or order release. This solution is efficient to keep the costs under control, but dis- regards the dynamics of the production systems, so that backorders and stock outs in the short term may occur. In this sense, the use of the dynamic modeling and simulation seems to be an interesting alternative or complement to other methodologies used in the production engineering area. The presented formulation is also relatively simple and easy to implement, which is an advantage in terms of use.

In order to implement it, the production system under consideration must be first modeled according to the methodology proposed in (Sagawa and Nagano, 2015a), which requires data related to the production routings, the historical demand for the end products, the product mix and the capacity of the machines (for more details, please refer to (Sagawa and Nagano, 2015a)). The mentioned methodology presents a generalization capability due to its modularity. The basic manufacturing entities, each one associated to its respective constitutive equation, may be arranged to represent different shop floor configurations, such as single machine, parallel machines, flow shop, job shop and open shop. The resulting state model will be a combination of the expressions that represent the involved entities. After this model is defined and implemented in a software for dynamic simulation of continuous systems, the adequate parameters of the controller must be defined, aiming to reduce the WIP levels and to smooth the oscillations. The generalization of the presented model requires an endeavor in this direction, since for each particular manufacturing system, a different type of controller with specific tuning could provide the best results. Thus, the control synthesis for different manufacturing systems is still an issue to be tackled.

The analysis of the results, especially in terms of the relative processing frequencies of the machines, show how much and when the capacity of each workstation should be increased or reduced, in order to achieve the desired levels of WIP. One practical limitation of the model refers to the level of aggregation of the data. Therefore, it can indicate that, for a certain period of time, a given station should work 5\% above its regular capacity, but it does not give indications regarding the detailed scheduling level, i.e. indications about which specific jobs/products to process with this extra capacity, in which sequence, and so on. In other words, the model is suitable for the planning level, instead of for the detailed execution level. In order to overcome this limitation, it could be used together with discrete event simulation models, or future efforts could be undertaken towards incorporating variables that concern the scheduling level, such as set up times of the machines or processing times of individual jobs.

\section{Final Remarks}

In this paper, we proposed a closed-loop simulation model with a PI controller to depict the dynamics of multiworkstation production system. The model was implemented and simulated in Matlab ${ }^{\circledR}$ and Simulink ${ }^{\circledR}$ con- 
sidering the warm-up of the system, when the initially empty buffers should be filled to desired levels, while the medium-term customer demand is fulfilled.

The results of exploratory tests showed that the saturation limits of the integral controller exert a relevant influence in the reduction of the work in process, but may also introduce some punctual instabilities. In future works, this parameter and the gains of the controllers could be simultaneously optimized, by means of the application of control theory tools and the execution of systematic experiments.

In terms of operations management, the proposed simulation model has the potential to give prescriptive directions about the dynamic adjustment of the capacities, in order to keep the WIP in the desired levels and the production costs relatively low, when the smoothing of capacity variations is set as a goal. In conventional production planning and control systems, based on MRP, the short term variations in production are avoided by means of the implementation of time fences to demand, planning or order release, disregarding the dynamics of the system and its ability to react to disturbances. In this sense, the presented tool can complement the existing tools for analysis and control of production systems and supply chains, allowing to take the perspective of the dynamics into consideration.

\section{Acknowledgements}

J.K.S would like to thank CNPq (Brazilian National Council for Scientific and Technological Development) for supporting this research (Grants 200648/2015-2).

\section{References}

Karl J Åström and P R Kumar. Control: A perspective. Automatica, 50(1):3-43, 2014.

Sven Axsäter. Coordinating Control of Production-Inventory Systems. International Journal of Production Research, 14 (6):669-688, 1976.

Reza Vatankhah Barenji, Ali Vatankhah Barenji, and Majid Hashemipour. A multi-agent RFID-enabled distributed control system for a flexible manufacturing shop. The International Journal of Advanced Manufacturing Technology, 71(9):1773-1791, Apr 2014. ISSN 14333015. doi:10.1007/s00170-013-5597-2.

E K Boukas and Z K Liu. Manufacturing systems with random breakdowns and deteriorating items. Automatica, 37: 401-408, 2001.

Ernest O Doebelin. System dynamics: modeling, analysis, simulation, design. Marcel Dekker, New York, 1998.

Juan Du, Jungup Park, Iiro Harjunkoski, and Michael Baldea. A time scale-bridging approach for integrating production scheduling and process control. Computers \& Chemical Engineering, 79 (Supplement C):59 - 69, 2015. ISSN 0098-1354. doi:https://doi.org/10.1016/j.compchemeng.2015.04.026.
G F Franklin, J.D. Powell, and Abbas Emami-Naeini. Feedback Control of Dynamic Systems. 011994.

M Ferney. Modelling and Controlling product manufacturing systems using bond-graphs and state equations: continuous systems and discrete systems which can be represented by continuous models. Production Planning \& Control, 11(1): 7-19, 2000.

Ali Gharbi and Jean Pierre Kenne. Optimal production control problem in stochastic multiple-product multiple-machine manufacturing systems. IIE Transactions, 35(10):941-952, 2003. doi:10.1080/07408170309342346.

R W Grubbström and A Molinder. Further theoretical considerations on the relationship between MRP, input-output analysis and multi-echelon inventory system. International Journal of Production Economics, 35(1-3):299-311, 1994.

R W Grubbström, M Bogataj, and L Bogataj. Optimal lotsizing within MRP Theory. Annual Reviews in Control, 34(1):89100, 2010.

W Hopp and M L Spearman. Factory Physics. Irwin, Boston, 2001.

Dmitry Ivanov and Boris Sokolov. Control and system-theoretic identification of the supply chain dynamics domain for planning, analysis and adaptation of performance under uncertainty. European Journal of Operational Research, 224(2): 313-323, 2013. doi:10.1016/j.ejor.2012.08.021.

J H Kim and N A Duffie. Performance of Coupled ClosedLoop Capacity Controls in a Multi-Workstation Production System. CIRP Annals - Manufacturing Technology, 55(1): 449-452, 2006.

M. A. S. Monfared and J. B. Yang. Design of integrated manufacturing planning, scheduling and control systems: a new framework for automation. The International Journal of Advanced Manufacturing Technology, 33(5):545-559, Jun 2007. ISSN 1433-3015. doi:10.1007/s00170-006-0476-8.

Javier Moreno-Valenzuela. Experimental comparison of saturated velocity controllers for dc motors. 59:254-259, 09 2008.

S.A. Munawar and R.D. Gudi. A multi-level, control-theoretic framework for integration of planning, scheduling and rescheduling. IFAC Proceedings Volumes, 37(9):613 - 618, 2004. ISSN 1474-6670. doi:https://doi.org/10.1016/S14746670(17)31877-3. 7th IFAC Symposium on Dynamics and Control of Process Systems 2004 (DYCOPS -7), Cambridge, USA, 5-7 July, 2004.

M Ortega and L Lin. Control theory applications to the production-inventory problem: a review. International Journal of Production Research, 42(11):2303-2322, 2004.

J.K. Sagawa and M.S. Nagano. Modeling the dynamics of a multi-product manufacturing system: A real case application. European Journal of Operational Research, 244(2), 2015a. ISSN 03772217. doi:10.1016/j.ejor.2015.01.017. 
Juliana Keiko Sagawa and Marcelo Seido Nagano. A Review on the Dynamic Decision Models for Manufacturing and Supply Chain. In Patricia Guarnieri, editor, Decision Models in Engineering and Management, pages 77-108. Springer International Publishing, Cham, 2015b. ISBN 978-3-319-11949-6. doi:10.1007/978-3-319-11949-6_5.

H Sarimveis, P Patrinos, C Tarantilis, and C T Kiranoudis. Dynamic modeling and control of supply chain systems: A review. Computers and Operations Research, 35(11):35303561,2008

H Scarf. The optimality of $(\mathrm{S}, \mathrm{s})$ policies in the dynamic inventory problem. Mathematical Methods in the Social Sciences, pages 196-202, 1960.

B. Scholz-Reiter and M. Freitag. Autonomous processes in assembly systems. CIRP Annals, 56(2):712 - 729, 2007. ISSN 0007-8506. doi:https://doi.org/10.1016/j.cirp.2007.10.002.

Susanne Schukraft, Sebastian Grundstein, Bernd Scholz-Reiter, and Michael Freitag. Evaluation approach for the identification of promising methods to couple central planning and autonomous control. International Journal of Computer Integrated Manufacturing, 29(4):438-461, 2016. doi:10.1080/0951192X.2015.1066032.
Virginia L.M. Spiegler, Mohamed M. Naim, Denis R. Towill, and Joakim Wikner. A technique to develop simplified and linearised models of complex dynamic supply chain systems. European Journal of Operational Research, 251(3):888 - 903, 2016. ISSN 0377-2217. doi:https://doi.org/10.1016/j.ejor.2015.12.004.

D. R. Towell. Dynamic analysis of an inventory and order based production control system. International Journal of Production Research, 20(6):671-687, 1982. doi:10.1080/00207548208947797.

Li-Chih Wang and Sian-Kun Lin. A multi-agent based agile manufacturing planning and control system. Computers \& Industrial Engineering, 57(2):620 - 640, 2009. ISSN 03608352. doi:https://doi.org/10.1016/j.cie.2009.05.015. Challenges for Advanced Technology.

H P. Wiendahl and J W. Breithaupt. Automatic production control applying control theory. International Journal of Production Economics, 63(1):33-46, 2000.

L Zhou, M M Naim, O Tang, and D R Towill. Dynamic performance of a hybrid inventory system with a Kanban policy in remanufacturing process. Omega, 34:585-98, 2006. 